\title{
0 uso da rede social Weibo na melhoria do domínio do sistema flexional em Português pelos aprendentes chineses
}

\author{
The use of social media Weibo to improve the mastery of the inflection \\ system in Portuguese by Chinese learners
}

Yuxiong Zhang ${ }^{1}$

António Moreira ${ }^{2}$

\begin{abstract}
Resumo
Sendo uma língua radicalmente diferente da sua primeira língua, os aprendentes chineses normalmente demonstram algumas dificuldades durante a aprendizagem inicial de português, especialmente em relação à flexão que não existe naquela. Considerando a popularização das redes sociais dentre a comunidade juvenil, aproveitamos a plataforma de microblogue de origem chinesa Weibo para criar um ambiente virtual de interação entre estudantes chineses e falantes nativos da língua portuguesa. Duas intervenções respectivamente com cinco estudantes portuguesas de mandarim e uma leitora portuguesa de Português Língua Estrangeira foram realizadas nos anos letivos 2018/2019 e 2019/2020 com os objetivos principais de entender as suas maiores dificuldades causadas pelos conceitos linguísticos adquiridos na sua língua materna durante a aprendizagem e identificar a influência trazida pela interação com os falantes nativos durante quatorze semanas no domínio do sistema flexional na língua portuguesa, nomeadamente, concordância verbal, formação dos tempos e modos verbais e concordâncias nominais de gênero e de número pelos aprendentes. Posteriormente, erros cometidos durante as atividades foram analisados consoante a ferramenta MaxQDA. De acordo com os resultados obtidos, alguns participantes chineses demonstraram um progresso no uso dos tempos e modos verbais e na concordância nominal de número, evidenciando as potencialidades da aplicação da rede social como uma abordagem possível para reforçar o domínio da flexão da língua portuguesa pelos falantes chineses iniciantes. Ainda assim, os estudantes revelaram certas dificuldades na aprendizagem, especialmente quanto aos conceitos que não existem no sistema linguístico da sua primeira língua.
\end{abstract}

Palavras-chave: Português Língua Estrangeira. Flexão. Rede social.

\begin{abstract}
As a language radically different from their first language, Chinese learners usually demonstrate some difficulties during initial Portuguese learning, especially in relation to the inflection which does not exist in their mother tongue. Considering the popularization of social media among the young people, we used the Chinese origin microblogging platform, Weibo to create a virtual environment for interaction between Chinese students and native speakers of Portuguese. Two interventions with respectively five Portuguese students of Mandarin and a Portuguese native teacher of Portuguese as a Foreign Language were carried out in the academic year 2018/2019 and 2019/2020 with the main objectives of understanding their major difficulties during the learning caused by the linguistic concepts acquired in their mother tongue and identifying the influence on the domain of the inflection system in the Portuguese language by the interaction with native speakers during fourteen weeks, which includes verbal agreement, formation of verbal tenses and modes and nominal agreement of gender and number by the learners. Errors during the activities were analyzed by MaxQDA. According to the findings obtained, some Chinese participants demonstrated progress in using verbal tenses and modes and in nominal number agreement, which highlights the potentialities of applying the social media as a possible approach to reinforce the initiated Chinese speakers' mastery of the inflection of Portuguese language. Still, the students revealed some difficulties, especially regarding the concepts that do not exist in the linguistic system of their first language.
\end{abstract}

Keywords: Portuguese as Foreign Language. Inflection. Social media.

\footnotetext{
1 Doutor em Multimídia em Educação. Dalian University of Foreign Languages, Dalian, Liaoning, China. Orcid: https://orcid.org/0000-0003-0305-0110 E-mail: yuxiongzhang@hotmail.com

${ }^{2}$ Doutor em Didática de Línguas Estrangeiras. Universidade de Aveiro, Aveiro, Aveiro, Portugal. Orcid: https://orcid.org/00000003-0040-2811 E-mail: moreira@ua.pt
}

LínguaTec, Instituto Federal de Educação, Ciência e Tecnologia do Rio Grande do Sul, Bento Gonçalves v. 6, n. 1, p. 01-15, jun. 2021. 


\section{Introdução}

Com a intensificação da cooperação entre a China e os países lusófonos, especialmente após o apoio da reconstrução pós-guerra de Angola e a fundação do Fórum para a Cooperação Econômica e Comercial entre a China e os Países de Língua Portuguesa (YE, 2014), a aprendizagem do português torna-se cada vez mais importante na China devido às oportunidades de trabalho que esta língua pode trazer. Porém, ao mesmo tempo que um número crescente de instituições superiores chinesas implementa cursos relativos à língua portuguesa, o desenvolvimento do ensino de português também está a enfrentar muitos desafios na China. Nas palavras de Godinho (2010, p.29), quanto mais distância em termos fonológicos, morfológicos e sintáticos entre a língua materna e a língua-alvo existe, fica mais complicado o processo de aprendizagem. E entre português e mandarim, não se encontram elementos nem estruturas efetivamente semelhantes e isto tornou a aprendizagem de português pelos estudantes chineses num caminho desamparado (BARBOSA, 2015).

Com efeitos, alguns processos morfossintáticos em português não existem no sistema linguístico da língua chinesa, um dos exemplos notáveis é a flexão (idem.). E o domínio das regras de concordância de número e gênero no sintagma nominal é reportado como uma das dificuldades constantes dos aprendentes chineses, pois não existe um parâmetro correspondente à concordância de plural na língua chinesa (GODINHO, 2010; GODINHO, 2014). E de acordo com Godinho (2010), a aquisição da flexão das formas irregulares é ainda mais desafiadora para os aprendentes iniciantes. Entretanto, Ma (2015) também referiu que cometer erros na concordância verbal era um fenômeno muito usual na aprendizagem de português tanto para os aprendentes chineses que estudam na China como para os que estudam em Portugal. E outra especulação comparativa, realizada por Ançã em 2008 em relação às dificuldades que os falantes ucranianos, cabo-verdianos e chineses sentiam quando falavam português, evidenciou que os chineses, em comparação com as outras duas comunidades, manifestaram mais dificuldades principalmente na concordância das formas verbais, utilização da preposição, formação dos tempos, vocabulário e concordância dos nomes em gênero.

Entretanto, os comportamentos linguísticos já adquiridos na língua materna podem produzir certos impactos na aprendizagem de línguas não maternas (MADEIRA, 2008). Assim, os conceitos linguísticos singulares em mandarim, uma língua analítica, podem tornar a aquisição de português, particularmente no que diz respeito à flexão nesta língua sintética, árdua e difícil para os falantes chineses. Além disso, dado a falta de ambiente linguístico da língua-alvo, as oportunidades limitadas de 
utilizá-la e treiná-la fora da sala de aula também são considerados efetivamente um fator importante que influencia diretamente a aprendizagem (ÁGUA-MEL, 2014).

\section{Redes sociais: uma possibilidade para a aprendizagem de línguas}

Considerando o fato da disponibilidade e acessibilidade da internet nos dias de hoje, o uso das redes sociais é um fator crescentemente comum dentro da comunidade de estudantes da geração atual que gastam bastante tempo on-line (KIRSCHNER; KARPINSKI, 2010; SCOTT; STANWAY, 2015). O uso das tecnologias da internet por motivos de socialização é considerado como uma caraterística generalizada da cultura juvenil de hoje (GRACE et al., 2014; OMOERA et al., 2018). Porém, tal como Burbules (2016) bem escreveu no seu estudo, as tecnologias proporcionam possibilidades verdadeiras e específicas e isto permite que as utilizem de uma forma diferente. Muitas vezes, os indivíduos utilizam as ferramentas de uma maneira criativa fora da sua intenção de uso original. Com efeito, as redes sociais também têm estado a receber cada vez mais atenção no mundo acadêmico nos anos recentes devido às suas potencialidades significativas. Em conformidade com o resultado da investigação realizada por Hwang e Fu (2019), que analisaram 97 artigos científicos relativamente à concepção e aplicação da aprendizagem de línguas baseada nos dispositivos móveis entre 2007 e 2016, o número de investigações desta área manifestou um crescimento anual estável.

À luz de Vygotsky (1978), a aprendizagem de línguas é considerada participativa, socialmente constituída e inseparável do contexto social. Os conhecimentos linguísticos, pragmáticos e culturais adquirem-se através das experiências sociais, em que os aprendentes exploram as regras subjacentes e implícitas de comunicação e interação, mediante o uso da língua-alvo numa sociedade (DUFF, 2010). Porém, sendo uma das dificuldades principais que a educação de línguas está a enfrentar na prática (WONG et al., 2016), a ausência do ambiente linguístico natural pode produzir influências negativas na aprendizagem.

Segundo as palavras de Kabilan, Amad e Abdin (2010), a aprendizagem não significa necessariamente que o processo tem de ocorrer num ambiente formal - dentro de uma sala de aula estandardizada e orientada por um instrutor. Aliás, a aprendizagem pode-se realizar em qualquer lugar, desde que existam interações significativas entre os aprendentes, originando a construção de conhecimentos. À vista disso, as redes sociais passam a ser uma possibilidade que, por um lado, suporta o uso linguístico dentro duma comunidade virtual e, por outro lado, considerando a sua popularização na geração jovem, pode ser facilmente aceita pelos aprendentes. Devido às suas caraterísticas peculiares, 
a aprendizagem de línguas pode ocorrer de uma forma ubíqua ao longo do tempo e do espaço com o uso das redes sociais, a qual se pode constituir num continuum de aprendizagem formal para aprendizagem informal fora de sala de aula, com aplicação de tecnologias móveis (MA, 2017). As plataformas de redes sociais superam as limitações físicas por fornecerem oportunidades comunicativas ilimitadas no mundo virtual, proporcionando possibilidades novas e adicionais para a aprendizagem de línguas (FEWELL, 2014; WONG et al., 2017; JONES, 2015). No entanto, o espaço social criado pelas redes sociais possibilita também a reutilização, enriquecimento e recontextualização dos conhecimentos e capacidades adquiridos na sala de aula, implicando uma aprendizagem profunda (WONG et al., 2017).

Se bem que a aplicação das tecnologias da informação e comunicação e os recursos multimídia na educação de línguas já não sejam atualmente um tópico muito novo no mundo acadêmico em Portugal, a sua utilização na especialidade do ensino de Português Língua Não Materna/Língua Estrangeira é, de fato, relativamente pouco estudada. Quanto ao ensino de português aos falantes de mandarim, a investigação é ainda mais escassa. Tal como Pissarra (2014, p. 211) bem referiu: "ensinar Português a um chinês não é o mesmo que ensinar a um aluno de matriz cultural ocidental". No entanto, Selwyn (2012) também chamou a atenção para a importância e necessidade de prestar atenção aos contextos global, nacional e regional e evitar uma suposição de cariz generalista e supranacional durante a investigação respeitante à educação e tecnologia. Por isso, decidimos focalizar em estudar a influência que 0 uso da rede social pode trazer na aprendizagem de Português Língua Estrangeira pelos aprendentes chineses iniciantes, especialmente com enfoque no sistema flexional da língua-alvo, neste caso, concordância verbal, concordância nominal de número e gênero e formação de modos e tempos.

\section{Metodologia}

\subsection{Participantes}

Cinco estudantes chineses do segundo ano do curso de Estudos Portugueses de uma universidade chinesa e cinco estudantes portuguesas do terceiro ano duma universidade portuguesa, que frequentavam a disciplina opcional de Chinês, participaram nesta investigação de forma voluntária no ano letivo 2018/2019 e, no ano letivo seguinte, a investigação foi novamente realizada com a participação voluntária de outros cinco estudantes do segundo ano do curso idêntico e uma leitora portuguesa que trabalhava também nesta universidade chinesa. 


\subsection{Seleção da ferramenta}

Para a criação do ambiente virtual de aprendizagem de línguas, a seleção de uma plataforma adequada será incontestavelmente imperativa que se tem de tratar igualmente como outras ferramentas tecnológicas didáticas e considerar as suas próprias características e desafios, escolhendo a ferramenta mais adequada para o caso (JENSEN, 2019). Nesse caso, consideramos as ferramentas de microblogue uma possibilidade que suporta uma aprendizagem situada motivada pela curiosidade, criatividade ou fatores práticos (CACCHIONE, 2015). Além disso, o uso autêntico da língua-alvo também se pode revelar quando as interações estão estabelecidas mediante este tipo de ferramenta, a qual, no entanto, também é reportada como uma maneira efetivamente mais fácil e relaxante para iniciar a produção de conteúdo na língua-alvo (RUIPÉREZ GARCÍA et al., 2011).

Devido à política peculiar da internet na China continental, a aplicação do Twitter ou outras ferramentas sociais de origem ocidental na prática pedagógica torna-se inexequível. Contudo, no seu estudo, Manca (2020) apelou para prestar mais atenção a outras plataformas além das mais emblemáticas, tais como o Twitter e o Facebook, visto que estas podem ter atualmente ainda mais popularidade entre os jovens e possuir também outras características peculiares. $E$ as aplicações sociais indígenas podem ainda conter padrões culturais particulares que influenciam inexoravelmente o seu uso para fins educativos (idem.). Tendo em conta esse fator, as redes sociais chinesas passam a ser um elemento ideal de investigação em relação ao desenvolvimento de um ambiente virtual de aprendizagem de português na China. Nesse caso, optamos por utilizar a ferramenta de microblogue de origem chinesa, Weibo como a plataforma onde se desenvolviam as atividades, cuja quantidade de utilizadores ultrapassou a do Twitter em maio de 2017 (BBC, 2017), possuindo 497 milhões de utilizadores mensais ativos. $^{3}$

\subsection{Métodos para realização das atividades}

De acordo com Sekiguchi (2012) e Toetenel (2014), para assegurar a aprendizagem efetiva, é necessário prestar atenção à natureza social da aprendizagem da língua-alvo e desenvolver um ambiente ativo de aprendizagem. Neste contexto, consideramos que a criação duma comunidade de

3 Disponível em: https://www.statista.com/statistics/272014/global-social-networks-ranked-by-number-of-users/. Acesso em: 12 dez. 2020 
aprendizagem com base no Weibo pode ser uma abordagem comunicativa possível, enquanto que a produção de sentido e aprendizagem através da interação se podem considerar como uma abordagem sociocultural. E sendo as condições essenciais para a aprendizagem de línguas (HSU, 2013) a exposição à língua-alvo e a interação com a sua comunidade linguística, também podem ser realizadas mediante a comunicação com as falantes nativas no espaço virtual.

A fim de simular o ambiente natural de uso da plataforma Weibo, o processo de aprendizagem baseia-se nas interações entre os aprendentes e falantes nativos da língua-alvo, realizadas mediante a criação de posts na língua-alvo consoante as instruções e requisitos publicados pelo organizador regularmente com a frequência de duas vezes por semana durante quatorze semanas. A todos os participantes foi solicitado escrever um pequeno texto a respeito dos tópicos sistemática e previamente organizados, incluindo questões culturais, rotina quotidiana, vida universitária, passatempos, filmes, livros e entre outros, com os objetivos de utilizar a língua-alvo das mais variadas maneiras possível, conceber as expressões que não sabem exprimir na língua-alvo, observar as formas de expressão dos falantes nativos e melhorar a sua produção linguística.

\subsection{Métodos de análise}

Todos os 28 textos publicados por cada participante durante as atividades em 14 semanas foram registrados por forma de captura de tela. Os 10 participantes produziram em média 90.6 palavras por texto (90.2 palavras na primeira intervenção e 91 palavras na segunda) e não houve nenhum requisito relativamente ao número de palavras durante o desenvolvimento das atividades. Posteriormente, aproveitamos a ferramenta MaxQDA para fazer uma análise qualitativa detalhada, em que todos os erros cometidos relativamente à flexão, designadamente, a concordância verbal, uso dos tempos e modos verbais e concordância nominal de número e gênero foram apontados e agrupados, cujo critério de avaliação alicerça-se em Nova Gramática do Português Contemporâneo, de Celso Cunha e Lindley Cintra (2000). Tomando em consideração a existência possível de diferença em relação ao número de palavras produzidas pelos participantes, optamos por apresentar o histograma realizado com base no número de erros com a intenção de demonstrar uma visão mais intuitiva em relação ao progresso obtido pelos aprendentes participantes durante as atividades. Entretanto, alicerçando-se na produção escrita dos participantes, aproveitamos também para identificar os principais gêneros de erros respeitantes à flexão existentes na aprendizagem iniciada de Português Língua Estrangeira pelos falantes chineses. 


\section{Discussão dos resultados}

\subsection{Concordância verbal e formação de tempos e modos}

A discordância verbal refere-se ao distúrbio respeitante à conjugação do verbo, por outras palavras, correspondência errada entre conjugação e pessoa gramatical. Durante as atividades, um erro comum foi a confusão entre a primeira conjugação verbal da primeira pessoa singular e a da terceira pessoa singular no pretérito perfeito. Além disso, conjugar o verbo "ser" no pretérito perfeito também é considerado uma dificuldade dos aprendentes chineses, uma vez que dois participantes confundiram a sua conjugação da primeira pessoa singular e a da terceira pessoa singular. No entanto, também foi descoberta uma dificuldade dos participantes chineses relativamente à conjugação do verbo "ouvir" na primeira pessoa singular do presente do indicativo, neste caso, três deles erraram em escrever o predicado. Com efeito, comparando os erros nos tempos ou modos verbais, não se trata a discordância do verbo como um tipo de erro muito grave, cuja frequência não ultrapassa 4 em cada desafio em ambas as intervenções (Figura 1).

As dificuldades dos dez aprendentes participantes centraram-se essencialmente no uso de tempos e modos verbais, manifestando-se sobretudo nos tempos (futuro, presente e passado), confusão entre modo indicativo e conjuntivo e uso incorreto do infinitivo, que incluem as situações em que os utilizaram quando não deviam e não os utilizaram quando deviam. $E$, de fato, a esmagadora maioria dos problemas concentrou-se no uso dos tempos. Sendo um fenômeno gramatical que não existe em mandarim, em que se utilizam os adjetivos para descrever tempo em vez de conjugar os verbos, os aprendentes chineses manifestaram mais dificuldades neste aspeto e muitas vezes não eram capazes de estar conscientes da existência do conceito do tempo passado quando o efeito ou resultado da ação realizada no passado se reflete no presente. Alguns erros mais representativos são: "estas fotos são (foram) tiradas por mim", "o livro é (foi) traduzido para 68 línguas" e "o inverno já chega (chegou)".

Sendo um conceito que também não existe efetivamente no sistema da língua chinesa, alguns estudantes chineses podem não ter estado familiarizados com o modo conjuntivo/subjuntivo durante a sua aprendizagem inicial de português, particularmente quando escrevem orações subordinadas regidas por verbos de desejo, emoção, sentimento e ordem. Um erro frequente cometido pelos participantes relaciona-se com o verbo "esperar" quando pretendiam exprimir o seu desejo subjetivo, tendo como exemplo, "espero que posso (espero poder) arranjar (arrumar) a minha residência bem também", "espero que posso (espero poder) cozinhar bem!", "espero que tenho (espero ter) um novo ano muito bom". 
Ademais, três dos participantes ignoraram ainda a necessidade do uso do conjuntivo/subjuntivo quando algumas conjunções específicas existiam, tais como "embora" e "talvez", utilizando o modo indicativo.

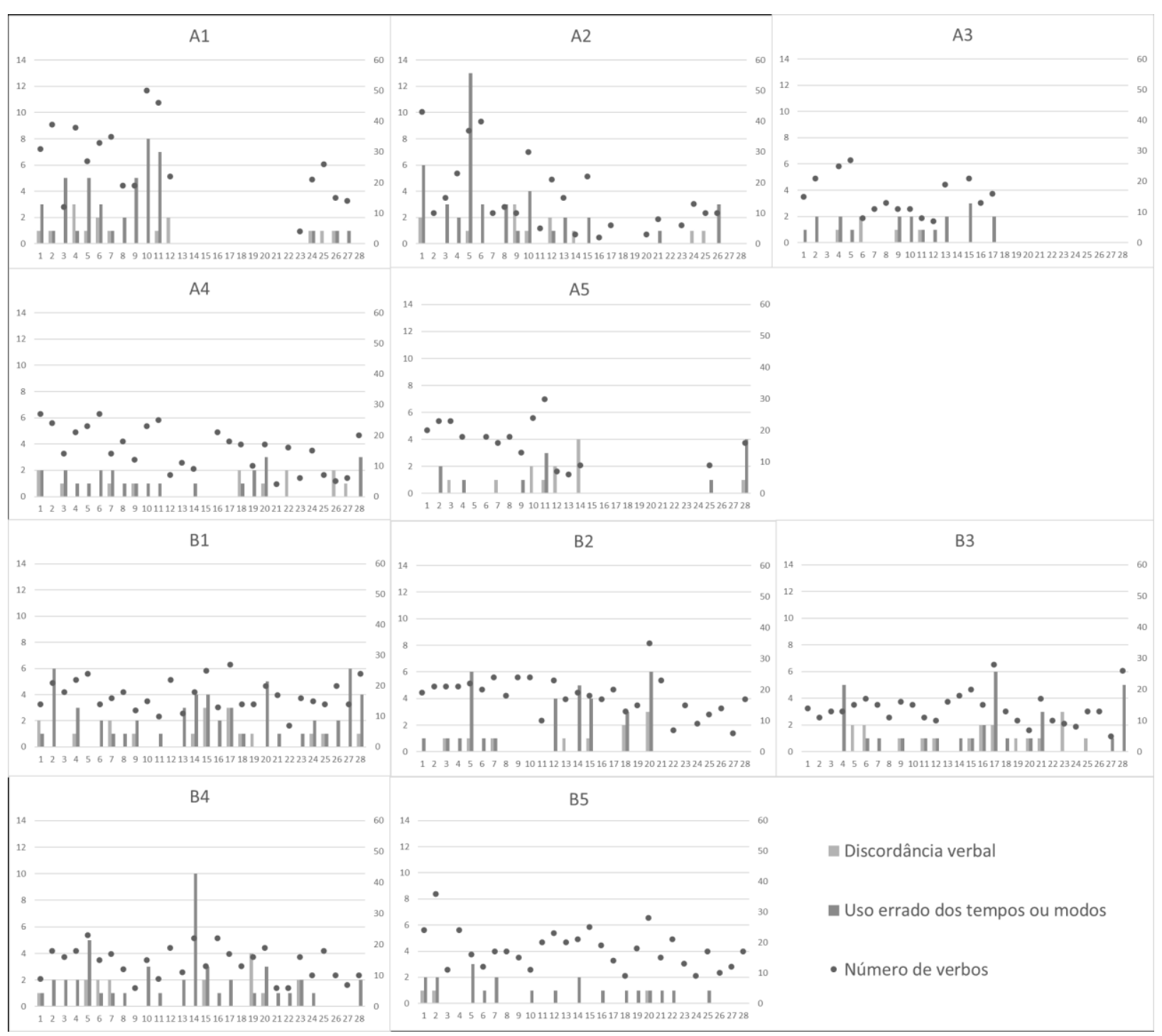

Figura 1. Erros relacionados com concordância verbal e formação de tempos e modos. Fonte: Os autores.

Não obstante, durante as atividades, os erros a respeito do infinitivo na verdade refletem dois gêneros de problemas dos aprendentes chineses, correspondendo ao seu uso inadequado e omissão do infinitivo. Por outras palavras, o uso inadequado do infinitivo pode revelar novamente o problema de ausência de consciência de conjugação no uso da língua-alvo que provavelmente os aprendentes iniciantes ainda não dominavam bem o sistema morfossintático na língua-alvo. De acordo com os textos publicados pelos participantes, que podem ainda não ter estado muito familiarizados com a língua portuguesa, por um lado, para eles, não era fácil de se lembrar de conjugar o verbo quando escreviam 
frases longas e, por outro lado, também podem ter falhado ao conjugar o segundo verbo conectado pela conjunção "e", embora tenham estado conscientes da utilização do infinitivo dos verbos quando existem verbos auxiliares, sendo considerado, com efeito, um erro comum durante as atividades.

Após o cálculo e agrupamento do número de erros, realizamos histogramas para visualizar 0 progresso dos dez aprendentes chineses das duas intervenções, que foram agrupados respectivamente em grupos A e B. De acordo com a Figura 1, pode-se dizer que não existe uma relação necessária entre o número de verbos usados e o de erros. $\mathrm{E}$, de forma geral, os erros referentes ao uso dos tempos e modos ocupa a posição dominante durante as atividades. Comparando com o número de usos errados dos tempos e modos, a ocorrência de discordância verbal desenrola-se numa flutuação ligeira nos cinco participantes da primeira intervenção. Contudo, os casos dos participantes A1 e A2 revelam de forma explícita uma tendência decrescente de erros relativamente aos tempos e modos. Os erros da A4, neste aspeto, permaneceram num nível relativamente estável, não havendo nenhum erro do desafio 21 ao 27 , embora tenham tido cometido três erros em relação ao uso do modo conjuntivo no último desafio. Contudo, em virtude da falta de contributos, não se pode identificar claramente se houve mudança relativa aos erros nos casos das outras duas participantes da primeira intervenção, nomeadamente, $A 3$ e A5. No caso da segunda intervenção, consideramos que a participante B2, que não tinha nenhum erro respeitante ao uso do verbo nos últimos oito desafios, a B4 e a B5 demonstram uma tendência decrescente relativamente ao uso errado do tempo verbal, enquanto a B1 pode ter continuado a sentir dificuldade neste aspeto. Os erros relativamente ao uso do verbo cometidos pelo participante B3 concentraram-se em sete desafios e não demonstram efetivamente uma mudança nítida. No que diz respeito à discordância verbal, todos os cinco participantes revelaram um comportamento relativamente positivo nos últimos cinco desafios neste caso, se bem que a participante B5 tenha manifestado um bom domínio da concordância verbal em geral. Os erros focalizam-se principalmente a meio das atividades nos casos dos participantes B1, B2 e B3, que se podem associar ao aumento da diversidade do conteúdo e da complexidade da estrutura sintática das suas produções.

\subsection{Concordâncias nominais de número e de gênero}

No que diz respeito à discordância, depende muito do conhecimento dos nomes e da familiaridade com o seu uso, especialmente os erros de concordância nominal de número. Quando a frase é longa ou existe um advérbio ou locução adverbial a seguir ao adjetivo, os participantes podem ficar confusos e seguir a terminação do advérbio, que não tem a formação do plural, falhando em manter 
a concordância de número. Alguns exemplos encontrados durante as atividades foram: "O Festival da Lua é um dos festivais tradicionais mais importante (importantes) no dia quinze de agosto do calendário lunar na China", "Os bolos da lua são tão doce (doces) às vezes", "Os preços são cada vez mais caro (caros) também" e "Penso que isso é normal no dormitório de rapazes porque somos um pouco 'preguiçoso (preguiçosos)'”. Além disso, os aprendentes esqueceram-se ainda de flexionar os adjetivos que terminam com "s", tendo como exemplo, "repolhos chinês (chineses)", "filmes português (portugueses)", "autores português (portugueses)" e "amigos português (portugueses)", revelando alguma negligência ou falta de familiaridade com a língua alvo.

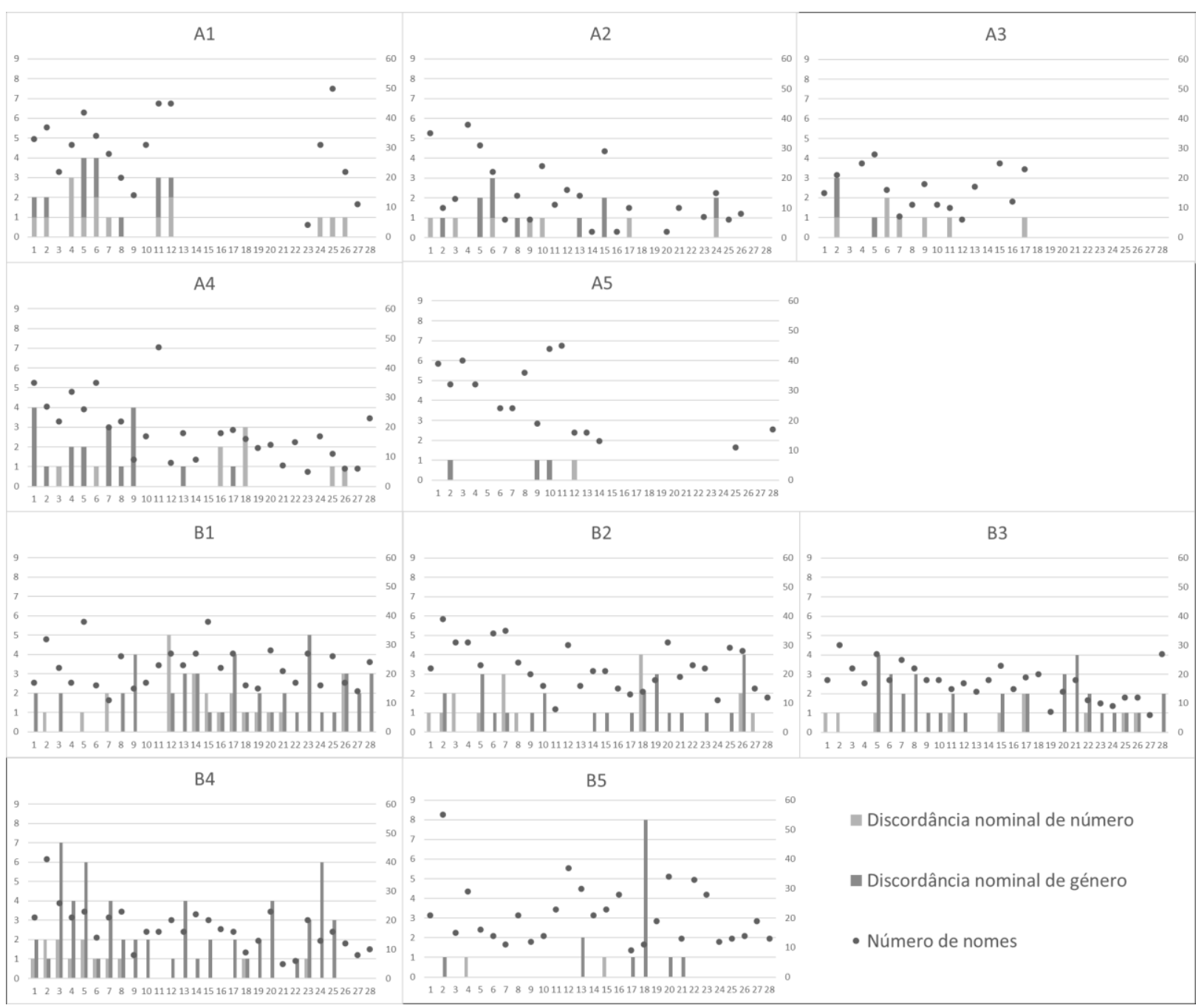

Figura 2. Erros relacionados com concordâncias nominais de número e de gênero.

Fonte: Os autores.

Todavia, de acordo com Barbosa (2015), muitas vezes os aprendentes chineses manifestam um hábito de procurar uma regra universal para memorização durante a aprendizagem de línguas estrangeiras e isto refletiu-se precisamente no fraco domínio dos participantes em relação ao 
conhecimento do gênero dos nomes. Os aprendentes iniciantes chineses podem assumir o gênero da palavra através da sua terminação, que, às vezes, podem implicar não acertarem e alguns erros que encontramos nas produções escritas pelos participantes das atividades foram: "a (0) problema", "0 (a) foto", "a (o) clima", "a (o) cinema", "o (a) refeição", "o (a) nutrição", "a (o) dia", "a (o/a) colega", "a (o) poeta", "a (o) poema", "a (o) programa" e "a (o) panda". E quanto aos nomes, cuja última letra não é "a" ou "o", os participantes manifestaram ainda mais dificuldades em manter a concordância nominal de gênero, tendo como exemplos, "um (uma) cidade", "cores diversos (diversas)", "neste (nesta) noite", "as (os) pastéis de nata", "um (uma) série de televisão", "a (o) segunda (segundo) exame", "uma (um) acidente", "muito (muita) carne", "o (a) miocardite", "alguns (algumas) árvores" e entre outros.

No entanto, outro tipo de erro mais típico é o uso do adjetivo em forma masculina quando as aprendentes escrevem com a perspectiva da primeira pessoa e utilizam o adjetivo como predicativo do sujeito e, com efeito, seis das oito participantes chinesas das duas intervenções cometeram erros desse gênero.

Em geral, os dez aprendentes participantes não manifestaram tanta dificuldade relativamente às concordâncias nominais em comparação com a discordância verbal e erros de tempos modos verbais. O número de erros mantém-se num nível relativamente baixo. De acordo com a Figura 2 que realizamos com base no número de erros em cada desafio cometido pelos dez aprendentes, a movimentação a respeito da discordância nominal de gênero apresenta uma flutuação relativamente ocasional, embora os participantes A1, A2 e A4 da primeira intervenção possam demonstrar uma certa melhoria. A situação relativamente à discordância nominal de número das participantes $A 2, B 1, B 2$ e B4 pode revelar um progresso positivo, já que os seus erros se focalizam no segundo ou primeiro terço das atividades, revelando um comportamento relativamente estável na última fase das atividades.

\section{Considerações finais}

Embora o número de participante deste estudo, que se caracteriza pelo seu caráter exploratório, tenha sido relativamente limitado e cada aprendente participante também tenha manifestado uma ligeira diferença em relação ao comportamento da produção escrita, em geral, alguns participantes demonstraram uma redução explícita relativamente ao uso errado dos tempos e modos verbais e discordância nominal de gênero em comum. No entanto, a discordância verbal e discordância nominal de número também se revelam uma melhoria em certo nível em caso de alguns estudantes chineses. $E$ esta melhoria pode ter resultado da familiaridade dos aprendentes com a língua-alvo à medida que estes 
utilizaram português para realizar os desafios e interagir com as falantes nativas. Segundo a teoria de correlação entre "frequência" e "proficiência" de Hawkins e Casillas (2008, apud HENG, 2014), o aumento da frequência de input e/ou output pode influenciar a proficiência e, pela sua vez, a proficiência também pode trazer impacto à frequência de produção. Através da análise do tipo de erros cometidos pelos participantes, não é difícil de chegar à conclusão que muitas vezes os problemas a propósito da flexão existentes na produção escrita relacionam-se com a falta de familiarização com o uso da língua-alvo, especialmente no contexto de que não se encontram conceitos de tempos e modos verbais nem de número e gênero nominal no sistema da língua chinesa. À vista disso, o aumento do contato com a língua-alvo disponibilizado pelo Weibo pode certamente ajudar os aprendentes iniciantes a estar mais familiarizados com o sistema morfossintático de português e isto é efetivamente o que a sala de aula tradicional de Línguas Estrangeiras não pode proporcionar, particularmente no que diz respeito à criação de um acesso ubíquo a um espaço virtual em que se reuniram os aprendentes e se visualizaram em tempo real as suas contribuições na língua-alvo, permitindo uma troca eficaz de conhecimentos. A aprendizagem, de fato, também não resulta meramente das interações escritas entre os participantes, mas também é influenciada pelas estruturas tecnológica, funcional, multimodal, sociocultural e sociolinguística do espaço virtual fornecida pela rede social (PIMMER et al., 2017). Assim, os participantes podem reforçar o seu conhecimento sobre a língua-alvo durante as atividades, reduzindo erros evitáveis, tais como, a discordância verbal e a nominal de número, as quais nem se referem a conceitos gramaticais muito complexos.

Ademais, o presente estudo também pode manifestar certos limites em virtude do número restrito de participantes e seu enfoque específico na questão da flexão na língua portuguesa que podem não representar completamente os problemas dos aprendentes chineses durante a sua aprendizagem de português. Entretanto, os aprendentes participantes eram estudantes do segundo ano do curso de Estudos Portugueses e aprendiam a língua-alvo somente há um ano e, por isso, os erros expostos nas atividades são, de fato, dificuldades mais representativas dos aprendentes iniciantes. À vista disso, não se pode determinar se 0 uso da rede social na aprendizagem também pode trazer influências positivas aos aprendentes avançados e os sem conhecimento nenhum sobre a língua-alvo. Contudo, em geral, pode-se dizer que a aplicação do Weibo na aprendizagem pode eventualmente influenciar de uma forma positiva o domínio do sistema flexional de português pelos aprendentes chineses iniciantes, ajudando a reforçar o seu conhecimento do uso da língua portuguesa. 


\section{Referências}

ÁGUA-MEL, C. O ensino do Português em Macau: Por que razão aprender só a escrever não chega? In: GROSSO, M. J.; GODINHO, A. P. C. (Ed.) O Português na China. Lisboa: Lidel, 2014.

BARBOSA, A. V. O papel da consciência (meta)linguística no ensino da língua portuguesa a alunos chineses. Letras \& Letras, v. 31, n. 2, p. 111-127, dez. 2015. http://doi.org/10.14393/LL62-v31n2a2015$\underline{6}$

BURBULES, N. C. How we use and are used by social media in education. Educational Theory, v. 66, n. 4, p. 551-565, ago. 2016. http://doi.org/10.1111/edth.12188

CACCHIONE, A. Creative use of Twitter for Dynamic Assessment in Language Learning classroom at the university. Interaction Design and Architecture(s) Journal, v. 24, p. 145-161, nov. 2015.

CUNHA, C.; CINTRA, L. F. L. Nova gramática do português contemporâneo. Lisboa: Edições João Sá da Costa. 2000.

DUFF, P. Language socialization. In: McKay, S.; Hornberger N. H. (Ed.), Sociolinguistics and language education. Clevedon, UK: Multilingual Matters, 2010.

FEWELL, N. Social networking and language learning with Twitter. Research Papers in Language Teaching and Learning, v. 5, n. 1, p. 223-234, fev. 2014. Disponível em: $<$ https://www.researchgate.net/profile/Norman_Fewell/publication/332931950_Social_networking_and_I anguage learning_with_Twitter/links/5cd241aa299bf14d957e7b37/Social-networking-and-languagelearning-with-Twitter.pdf>. Acesso em: 12 dez. 2020

GODINHO, A. P. A aquisição da concordância de número e a sua relação com a aquisição da concordância de género: Um estudo realizado com aprendentes chineses de Português L2. In: Marçalo, M. J. et al. (Ed.) Língua portuguesa: Ultrapassar fronteiras, juntar culturas. Évora: Universidade de Évora, 2010.

GODINHO, A. P. Aquisição da concordância em género e número no contexto de ensino/aprendizagem de Português Língua Estrangeira em Macau. In: GROSSO, M. J.; GODINHO, A. P. C. (Ed.) O Português na China. Lisboa: Lidel, 2014.

GRACE, E.; RAGHAVENDRA, P.; NEWMAN, L. Learning to use the internet and online social media: what is the effectiveness of home-based intervention for youth with complex communication needs? Child Language Teaching and Therapy, v. 20, n. 2, p. 141-157, jan. 2014. http://doi.org/10.1177/0265659013518565

HENG, S. A. S. Aquisição de morfologia verbal do Português europeu por aprendentes chineses: Um estudo piloto. In: GROSSO, M. J.; GODINHO, A. P. C. (Ed.) O Português na China. Lisboa: Lidel, 2014.

HSU, L. Leveraging interactivities on social networking sites for EFL learning. International Journal of English Language Education, v. 1, n. 3, p. 244-270, jul. 2013. http://doi.org/10.5296/ijele.v1i3.4063 
HWANG, G.; FU, Q. Trends in the research design and application of mobile language learning: A review of 2007-2016 publications in selected SSCl journals. Interactive Learning Environments, v. 27, n. 4, p. 567-581, jun. 2018. http://doi.org/10.1080/10494820.2018.1486861

JENSEN, L. J. Integrating Social Media into Online Education. In: GREEN, L. S. (Ed.) Librarians as Online Course Designers and Instructors, Library Technology Reports, v. 55, n. 4, p. 27-30, maio/jun. 2019. Disponível em: <https://journals.ala.org/index.php/ltr/article/view/7003>. Acesso em: 12 dez. 2020

JONES, A. Social media for informal minority language learning: Exploring Welsh learners' practices. Journal of Interactive Media in Education, v. 1, p. art7, abr. 2015. http://doi.org/10.5334/jime.ak

KABILAN, M. K.; AHMAD, N.; ABIDIN, M. J. Z. Facebook: An online environment for learning of English in institutions of higher education? Internet and Higher Education, v. 13, p. 179-187, jul. 2010. http://doi.org/10.1016/j.iheduc.2010.07.003

KIRSCHNER, P. A.; KARPINSKI, A. C. Facebook and academic performance. Computers in Human Behavior, v. 26, p. 1237-1245, nov. 2010. http://doi.org/10.1016/i.chb.2010.03.024

MA, Q. A multi-case study of university students' language-learning experience mediated by mobile technologies: A socio-cultural perspective. Computer Assisted Language Learning, v. 30, n. 3-4, p. 183203, mar. 2017. http://doi.org/10.1080/09588221.2017.1301957

MA, X. Concordância verbal na língua portuguesa: Principais problemas para alunos chineses e portugueses. 2015. 92f. Dissertação (Mestrado em Línguas, Literaturas e Culturas) - Departamento de Língua e Cultura, Universidade de Aveiro, Aveiro, 2015.

MADEIRA, A. Aquisição de L2. In: OSÓRIO, P; MEYER, R. M. (Ed.) Português Língua Segunda e Língua Estrangeira. Lisboa: Lidel, 2008.

MANCA, S. Snapping, pinning, liking or texting: Investigating social media in higher education beyond Facebook. The Internet and Higher Education, v. 44, jan. 2020. http://doi.org/10.1016/j.iheduc.2019.100707

OMOERA, O. S.; AIWUYO, O. M.; EDEMODE, J.; ANYANWU, B. Impact of social media on the English language writing abilities of undergraduates in Ekpoma, Nigeria. GIST Education and Learning Research Journal, v. 17, p. 59-80, jul. 2018. http://doi.org/10.26817/16925777.412

PIMMER, C.; CHIPPS, J.; BRYSIEWICZ, P.; WALTERS, F.; LINXEN, S.; GRÖHBIEL, U. Facebook for supervision? Research education shaped by the structural properties of a social media space. Technology, Pedagogy and Education, v. 26, n. 5, p. 517-528, ago. 2016. http://doi.org/10.1080/1475939X.2016.1262788

PISSARA, R. A. O ensino do Português na China: Relato de uma experiência. In: GROSSO, M. J.; GODINHO, A. P. C. (Ed.) O Português na China. Lisboa: Lidel, 2014.

RUIPÉREZ GARCÍA, G.; CASTRILLO DE LARRETA-AZELAIN, M. D.; GARCÍA CABRERO, J. C. El uso de Twitter para mejorar la competencia de la expresión escrita en el aprendizaje de lenguas extranjeras. 
Arbor: Ciencia, pensamiento y cultura, v. 3, p. 159-163, dez. 2011. http://doi.org/ 10.3989/arbor.2011.Extra-3n3138

SCOTT, O. K. M.; STANWAY, A. R. Tweeting the lecture: how social media can increase student engagement in higher education. Sport Management Education Journal, v. 9, p. 91-101, out. 2015. http://doi.org/10.1123/SMEJ.2014-0038

SEKIGUCHI, S. (2012). Investigating the effects of Twitter on developing a social learning environment to support Japanese EFL students' self-regulated learning. In: INTERNATIONAL CONFERENCE "ICT FOR LANGUAGE LEARNING", 5. 2012, Florence. Proc... Florence: Pixel. Disponível em: $<$ https://conference.pixel-online.net/conferences/lCT4LL2012/common/download/Paper_pdf/279-IBT56FP-Sekiguchi-ICT2012.pdf>. Acesso em: 12 dez. 2020.

SELWYN, N. Ten suggestions for improving academic research in education and technology. Learning, Media and Technology, v. 37, n. 3, p. 213-219, abr. 2012. http://doi.org/10.1080/17439884.2012.680213

TOETENEL, L. Social networking: A collaborative open educational resource. Computer Assisted Language Learning, v. 27, n. 2, p. 149-162, jul. 2013. http://doi.org/10.1080/09588221.2013.818561

Vygotsky, L. Mind in society: The development of higher psychological processes. Cambridge, MA: Harvard University Press. 1978

WONG, L.; CHAI, C.; AW, G. Seamless language learning: Second language learning with social media. Media Education Research Journal, v. 50, n. 25, p. 9-20, ago. 2016. http://doi.org/10.3916/C50-2017-01

WONG, L.; KING, R. B.; CHAI, S.; LIU, M. Seamlessly learning Chinese: contextual meaning making and vocabulary growth in a seamless Chinese as a second language learning environment. Instructional Science, v. 44, n. 5, p. 399-422, ago. 2016. http://doi.org/10.1007/s11251-016-9383-z

YE, Z. Algumas considerações sobre a expansão do ensino da língua portuguesa na China. In: GROSSO, M. J.; GODINHO, A. P. C. (Ed.) O Português na China. Lisboa: Lidel, 2014.

Data de submissão: 12/12/2020. Data de aprovação: 14/04/2021. 